\title{
Pendekatan Games Dalam Meningkatkan Motivasi Belajar Siswa Bagi Relawan Gemma Insani Indonesia
}

\author{
Tita Puspitasari a,1, Dwinesa Anggraeni ${ }^{\text {b,2 }}$ \\ ${ }^{\text {a }}$ Program Studi Pendidikan Bahasa Inggris \\ ${ }^{\mathrm{b}}$ Fakultas Bahasa dan Seni Universitas Indraprasta PGRI \\ ${ }^{1}$ Tita1984ps@gmail.com ; ${ }^{2}$ dwinesaanggraeni@yahoo.com
}

ARTICLE INFO

Keywords

Games

Motivation

Volunteers
ABSTRACT

The aim of this workshop is to become Gemma Insani volunteers have got the ability of classroom management and basic knowlegde about education psychology is related how the way to give the students motivate by using games in learning process. The event is followed by 25 volunteers Gemma Insani Depok. The methods are used in the workshop such presentation, discussion and question and answer, and simulation from the volunteers. The result of the workshop are (1) to train the volunteers' teaching ability who have got different education background. In application kinds of games that used for all subjects in education level. This event can help hopefully to motivate the students in learning. (2) to use kind of methods in learning process so the student will not feel bored, and (3) be able to have creative thinking in creating or making games based on student-education level.

\section{PENDAhuluaN}

Pada tahun 2010-2012 GEMBOK (gerakan edukasi, empati, dan entrepreneur mahasiswa Bogor-Depok) merupakan awal mula terbentuknya Gemma Insani. Berawal dari 10 mahasiswa yang memiliki pemikiran, latar belakang yang berbeda, namun memiliki cita-cita yang sama yakni membuat gerakan perubahan untuk berpartisipasi menciptakan masyarakat Indonesia yang lebih baik.

Pada tahun 2013 diawali dengan rasa gelisah dengan nama GEMBOK yang sudah tidak lagi relavan dengan anggota yang berada di dalamnya, karena dinilai terlalu idealis dengan memakai nama kota tertentu (Bogor-Depok) sedangkan jumlah anggota yang semakin bertambah di luar dari domisili kota itu. Maka pada bulan Mei 2013 GEMBOK dengan resmi mengganti nama mereka denga Gemma Indonesia Community.

Gemma Indonesia Community berperan aktif mengikuti kegiatan-kegiatan antar-komunitas dan antar-pendidikan yang ada di Jabodetabek. Mengadakan khitanan masal, donor darah, mendirikan sekolah sosial, santunan anak yatim dan dhuafa, serta kegiatan fund raising untuk meringankan penderitaan warga sekitar.

Tepatnya pada tanggal 17 Agustus 2014 komunitas ini sepakat membentuk sebuah Yayasan yang diberikan nama Yayasan Gemma Insani Indonesia dengan tidak mengubah visi awal yakni dibidang education, empathy (humanity), dan entrepreneurship.

Perjalanan Yayasan Gemma Insani Indonesia hingga saat ini telah melahirkan salah satu program dalam bidang pendidikan yaitu Rumah Belajar Indonesia Kreatif atau dikenal RUBIK. Rumah belajar ini telah dibangun di beberapa wilayah Depok dan Bogor diantaranya: Rubik 1 yang terletak di Kampung Sawah Bojong Gede Bogor, Rubik 2 di Kampung Lio Bogor, Rubik 3 di Bojong Sari Depok, dan Rubik 4 yang terletak di Sekretariat Gemma Insani Sugutamu, Depok.

Relawan adalah orang yang secara sukarela menyumbangkan waktu, tenaga, pikiran, dan keahliannya untuk menolong orang lain dan sadar bahwa tidak akan mendapatkan upah atau gaji atas apa yang telah disumbangkan. Jumlah relawan untuk saat ini yang tergabung dalam Gemma sekitar 20 anggota dengan pengurus. Karena Gema Insani dibangun berdasarkan prinsip sosial sehingga jumlah relawan kadang tidak tetap. Latar belakang pendidikan relawan pun berbeda-beda. 
Sebagian sudah menyelesaikan pendidikannya, sebagian lagi masih berstatus mahasiswa seperti dari BSI, UIN, UNINDRA, IPB, BSI, STAI Syamsul Ulum, PNJ, Gunadarma, bahkan ada yang masih berstatus pelajar SMU.

Belajar tidak senantiasa berhasil, tetapi sering ada hal-hal yang bisa mengakibatkan kegagalan atau setidak-tidaknya menjadikan gangguan yang bisa menghambat kemajuan belajar. Banyak yang dapat menghambat dan menganggu kemajuan belajar, salah satu faktor yang menghambat kemajuan belajar adalah motivasi dan perhatian siswa terhadap bahan pelajaran.

Ada berbagai cara yang dapat dilakukan oleh seorang guru atau pengajar untuk meningkatkan motivasi belajar para peserta didik, salah satunya dengan penggunaan metode atau teknik pengajaran dan kegiatan pembelajaran yang beragam. Hal ini dikarenakan setiap metode pembelajaran memiliki keunggulan dan kelemahan masing-masing. Tidak ada satu metode pembelajaran yang dianggap ampuh untuk segala situasi. Suatu metode pembelajaran dianggap efektif pada suatu situasi, namun belum tentu ampuh untuk situasi lain. Maka dari itu para pengajar dianjurkan untuk menggunakan metode pembelajaran bervariasi, hal ini sangat penting dilakukan agar suasana proses pembelajaran menjadi menyenangkan dan tidak membuat para siswa merasa bosan atau jenuh, serta agar para siswa dapat menerima apa yang telah dipelajarinya dengan baik.

Kini telah banyak sekali metode pembelajaran yang menarik yang membuat siswa ikut terlibat aktif dalam proses pembelajaran yang dapat digunakan oleh pengajar untuk menciptakan suasana belajar yang menyenangkan sekaligus dapat meningkatkan motivasi dalam belajar, salah satunya yaitu dengan menerapkan permainan (games) sebagai alternatif dalam proses pembelajaran.

Setelah melakukan observasi dan diskusi, tim abdimas menyimpulkan bahwa permasalahan mitra terjadi karena adanya sistem pengajaran yang monoton dan tidak terstruktur yang menyebabkan kejenuhan bagi siswa. Perbedaan latar belakang pendidikan yang berbeda-beda juga menjadi faktor penentu kualitas penyampaian materi kepada siswa. Karena Gemma Insani berfokus pada kegiatan sosial sehingga para pengajar adalah relawan yang berasal dari tingkat pendidikan yang berbeda-beda sehingga wawasan mengenai pengajaran yang dimulai dari metode/teknik yang digunakan, manajemen kelas, materi, serta pengetahuan dasar mengenai psikologi pendidikan masih kurang. Beberapa relawan mungkin bukan berasal dari lulusan universitas yang berfokus pada pendidikan atau pengajaran. Bermacam- macamnya latar belakang pendidikan relawan berdampak pada kurang termotivasinya siswa. Penggunaan metode pengajaran yang kurang terstruktur dan terorganisis karena minimnya pengetahuan dasar dalam pengajaran mendorong tim tertarik memberikan pelatihan mengenai metode pengajaraan yaitu dengan pendekatan games. Pendekatan games adalah salah satu cara dalam memotivasi siswa dalam proses belajar.

\section{KAJIAN PUSTAKA}

\subsection{Motivasi}

Dalam melakukan suatu kegiatan, seseorang harus memiliki motivasi bisa berupa tujuan maupun proses pemenuhan kebutuhan, tanpa terkecuali dalam proses pendidikan terutama pembelajaran.

Santrock (2007) mendefinisikan motivasi merupakan proses yang memberi semangat, arah, dan kegigihan perilaku yang penuh energi, terarah, dan bertahan lama. Dengan kata lain, motivasi merupakan proses yang kompleks antara keinginan, semangat, dan keyakinan teguh dari individu untuk mencapai tujuan yang diinginkan. Sedangkan menurut Malik (2008), motivasi merupakan perubahan energi dalam pribadi seseorang yang ditandai dengan timbulnya perasaan dan reaksi untuk mencapai tujuan, memiliki dua komponen yakni 1) komponen dalam ialah perubahan dalam diri seseorang, keadaan tidak merasa puas dan ketegangan psikologis, dan 2) komponen luar ialah apa yang diinginkan seseorang dan tujuan yang menjadi arah kelakuannya.

Jadi motivasi adalah hasil keinginan seseorang untuk memenuhi kebutuhannya mulai dari perubahan sikap sampai berbagai usaha agar tujuannyaa tercapai. Dapat diasumsikan bahwa motivasi merupakan proses yang berbeda-beda sesuai dengan tingkat kebutuhannya dari dalam dirinya. Bila seseorang memiliki motivasi yang tinggi, bukan hal yang mustahil dia mampu memenuhi keinginan yang sebelumnya hanya merupakan impian. 


\subsubsection{Motivasi Belajar}

Pada hakikatnya, pengajar di dalam proses belajar mengajar membutuhkan motivasi sebagai kebutuhan yang penting. Tanpa adanya motivasi peserta didik tidak akan memiliki kemauan dalam belajar. Oleh karena itu, guru harus mampu meningkatkan motivasi belajar peserta didik baik dari dalam maupun dari luar diri peserta didik. Proses peningkatan motivasi bisa dilakukan dengan memilih motede pembelajaran yang tepat agar tujuan pembelajaran yang diharapkan dapat tercapai.

Sanjaya (2008) mendefnisikan bahwa motivasi belajar adalah dorongan yang memungkinkan peserta didik untuk bertindak atau melakukan sesuatu karena peserta didik merasa membutuhkan. Dorongan tersebut terdapat dari dalam atau dari lingkungan terdekat. Apabila peserta didik sudah merasa dibutuhkan, peserta didik tersebut akan bergerak dengan sendirinya untuk mengetahui kebutuhannya. Oleh karena itu, perlu bagi guru untuk menunjukkan pentingnya pengalaman dan materi belajar bagi kehidupan peserta didik sehingga nantinya siswa akan belajar bukan hanya sekedar mendapatkan nilai atau pujian tetapi didorong oleh kebutuhannya sendiri.

Enggen dan Kauchak (2007) menambahkan, in general, motivated students have more positive attitudes toward school and describe school as satisfying, persist on difficult tasks and cause fewer management problems, process information in depth and excel in classroom learning experiences. Jadi, ciri dari siswa yang memiliki motivasi antara lain tingkah aku yang baik di sekolah, selalu berusaha dalam mengerjakan tugas yang sulit maupun masalah yang dihadapi, dan memproses informasi secara mendalam baik di dalam atau luar proses pembelajaran.

Sesuai dengan teori di atas, motivasi belajar merupakan dorongan yang memungkinkan siswa untuk bertindak atau melakukan sesuatu karena siswa merasa membutuhkan yang terdapat dari dalam atau lingkungan terdekat peserta didik untuk mencapai suatu tujuan tertentu, dengan bertingkah laku yang baik di sekolah, selalu berusaha dalam mengerjakan tugas yang sulit maupun masalah yang dihadapi, kemudian memproses informasi secara mendalam baik di dalam ataupun di luar dalam proses pembelajaran.

Fakta di lapangan menunjukkan bahwa setiap peserta didik memiliki motivasi belajar yang berbeda-beda. Salah satu cara untuk mengorganisir banyaknya informasi mengenai motivasi adalah mempertimbangkan factor-faktor yang memperngaruhi motivasi itu sendiri. Menurut Woolfolk dan Nicolich (2004) faktor tersebut terdiri dari sikap, kebutuhan, afeksi kompetensi, dan penguatan.

\subsection{Games}

Suatu permainan (games) adalah suatu aktifitas yang mengandung unsur peraturan, tujuan dan rasa kesenangan. Ada dua jenis permainan yang bisa dilakukan yaitu permainan kompetensi (competitive games) dimana permainan atau tim berlomba untuk menjadi yang pertama, mencapai tujuan, dan permainan kerjasama (cooperative games) dimana pemain dan tim bekerja sama untuk mencapai tujuan. Jill Hadfield (1984:5) menyatakan a game is an activity with rules, a goal and an element of fun. One of the most important reason for using games is simply that they are immensely enjoyable for both teacher and student Mengajak peserta didik bermain sambil belajar ternyata memberi banyak manfaat bagi guru dan peserta didik :

1. Bagi guru; (a) Guru akan lebih mudah memberikan penjelasan suatu materi pembelajaran, bila diterapkan dalam bentuk permainan.(b) Guru juga dapat membuat suasana kelas menjadi lebih hidup. (c) Guru akan mendapatkan prestasi tersendiri dimana guru mampu membuat semua siswanya berpartisipasi aktif selama proses belajar mengajar di kelas.

2. Bagi siswa; Siswa akan lebih mudah memahami materi pelajaran yang sedang dipelajari karena disajikan dalam bentuk permainan. (a) Permainan dapat mengurangi atau bahkan menghilangkan kebosanan siswa belajar di dalam kelas. (b)Siswa dapat lebih mudah dan cepat mengingat materi pembelajaran.Siswa menjadi aktif di kelas. (c) Siswa akan memiliki rasa solidaritas dan sportifitas di kalangan teman-temanya.

\subsubsection{Jenis-Jenis Games}

\subsubsection{Word Chain}


Word chain atau dikenal dengan English Shiritori Game, Last and First or Grab on Behind adalah permainan menyambung kata, konsonan, atau huruf. Roger Smith dari The Bewbush Academy, West Sussex mengatakan :

' Word Chain improve your students' spelling with this easy and fun word game. Good plenary or extension activity. Can be played in small groups or as a whole class. The idea is to create a word chain in which the last two letters of a word form the first two letters of the next. Word chains help students with their spelling because they are encouraged to recognize possible letter combinations. It sounds complicated but kids quickly pick up the rules and the scoring system."

Abdullah (1993) mengatakan permainan menyambung kata mampu memperdalam kata-kata Bahasa Inggris (dapat digunakan untuk mempelajari bahasa lain) dengan latihan menyebutkan kata dari bahasa yang dipelajari.

\subsubsection{Whispering Game}

Salah satu jenis permainan yang paling efektif untuk dijadikan media pembelajaran adalah whispering game. Game berbisik-bisik atau whispering game adalah permainan berantai dimana siswa diinstruksikan untuk meneruskan kata yang telah dibisikkan oleh guru kepada siswa yang ada pada urutan rantai pertama. Tata caranya, siswa berbaris kemudian guru membisikkan kata kepada siswa yang ada pada salah satu ujung barisan. Kemudian siswa tersebut membisikkan kata/kalimat yang didengar kepada siswa disebelahnya dan seterusnya. Setelah kata/kalimat yang dibisikkan sampai kepada siswa yang berada di barisan ujung terakhir, maka setiap siswa wajib melaporkan/mengucapkan kata yang telah mereka dengar.

\subsubsection{Star Wars}

"Competition is a dirty word. In our modern world we often exclude it in favor of cooperation and other current pedagogical buzzwords." Penjelasan yang dipaparkan oleh Steely (2013) dalam IB Dunia Teachers' Conference 2013. Walaupun demikian, dalam dunia pendidikan kompetisi dapat digunakan untuk memotivasi siswa. Star wars adalah koperatif dan kompetitif permainan yang mampu memfasilita si semangat siswa dalam bentuk persaingan. Tetapi, permainan ini menekankan akan pentingnya kompetensi tanpa melupakan kemampuan siswa dalan berkerjasama atau bersikap koperatif. Permainan ini mampu melatih kemampuan lainnya seperti listening, oral communication, dan mampu membantu siswa mengingat kembali materi yang sudah diajarkan di kelas. 'Teachers can use competition along with cooperation to boost student motivation and learning in their classroom. Teachers can incorporate such competitions to benefit students to express their selves in achieving something."' Seperti yang ditambahkan Steely (2013).

How to play;

a. Split the students into groups; 4/5 students for each group.

$b$. Tell them that each group has 5 stars.

c. If any group can answer the question correctly, they can take other group' star.

$d$. We can put any material we've been learned in class to check their understanding; I prefer to make questions related to grammar, vocabulary, math, history, and other knowledge (social studies).

e. For the group who get more stars than the other group, then they are the winner.

\section{METODE}

Kegiatan pelatihan ini dilaksanakan dengan cara; (1) Presentasi Tim, (2) Diskusi dan Tanya Jawab, (3) simulasi Kerja (performance) dari peserta. Kegiatan ini diikuti oleh 25 relawan. adapun 
performance yang dilakukan oleh rewalan yaitu mensimulasikan games sebagai metode pengajaran untuk memotivasi siswa.

\section{HASIL DAN PEMBAHASAN}

Pelatihan dalam meningkatkan kemampuan mengajar relawan yang dilaksanakan di sekretariat Gemma Insani Indonesia dengan pembahasan mengenai Pendekatan Games Dalam Meningkatkan Motivasi Siswa Bagi Relawan Gemma Insani Indonesia adalah salah satu upaya dalam meningkatkan mutu dan pelayanan di bidang pendidikan. Kebutuhan akan kesetaraan dan kesempatan mendapatkan pendidikan yang sama bagi anak-anak Indonesia mendorong berdirinya cikal bakal Yayasan Gemma Insani Indonesia.

Dengan mengajak para generasi muda untuk ikut serta dalam kegiatan sosial dengan mengajar anak-anak yang belum mendapat kesempatan mengenyam pendidikan formal, para relawan ini berasal dari berbagai latar belakang pendidikan yang berbeda-beda. Mulai dari relawan yang masih duduk di bangku SMU hingga mereka yang telah lulus kuliah dan bekerja. Sebagian dari mereka bukan berasal dari lulusan yang berorientasi pada pendidikan. Sehingga diharapkan dengan dilaksanakannya pelatihan ini mampu menambah wawasan relawan dalam teaching method, classroom management, dan pengetahuan dasar mengenai psikologi pendidikan yang berfokus pada motivasi siswa. Kegiatan pengabdian masyarakat ini dilakukan ke dalam beberapa tahap; observasi, sosialisai (presentasi), implementasi, dan review/feedback.

Tahap pertama yaitu observasi sebagai cara untuk mengidentifikasi problematika yang ada dengan ikut serta dalam proses belajar mengajar. Hal ini dilakukan sebagai upaya pengenalan dan pendekatan terhadap siswa serta untuk menilai langsung kemampuan siswa dan penguasaan pengajar dalam menyampaikan materi. Dalam tahap ini, tim abdimas menemukan bahwa adanya proses pengajaran yang tidak tersistem sehingga menyebabkan kurangnya motivasi belajar siswa. Kemudian beberapa relawan bukan berasal dari latar belakang jurusan pendidikan dan ada yang masih duduk di bangku SMU. Dikarenakan sekolah ini dibangun dengan prinsip sosial dimana siswa dibebaskan dari segala biaya dengan tujuan setiap anak Indonesia berhak mendapatkan pendidikan, sehingga para relawan berasal dari tingkat dan latar pendidikan yang berbeda-beda. Dengan alasan utama tersebutlah, tim memilih yayasan ini sebagai tempat penelitian dan pengabdian masyarakat. Tahap kedua yaitu sosialiasasi. Sosialisasi dilakukan dengan pelatihan dan pemberian materi dengan menjabarkan teori dasar mengenai motivasi dan pendekatan games dalam proses belajar mengajar. Tim membagi tiga sesi dalam pembahasan materi. Selanjutnya memperkenalkan media games serta menjelaskan step-step yang diperlukan dalam melakukan games tersebut. Sosialisasi dilakukan dengan implementasi games dalam proses belajar dengan mengajak para relawan untuk ikut serta dalam penggunaan games tersebut secara langsung. Dalam tahap ini dapat dilihat respon relawan terhadap media games tersebut apakah mampu memotivasi mereka sebelum games tersebut mereka gunakan di kelas. Setelah implementasi, tim memberikan sesi terakhir untuk tanya-jawab seputar materi dan sesi sharing bagi mereka yang menghadapi problematika mengenai pengajaran dengan menawarkan beberapa solusi. Tahap ketiga adalah evaluasi dan timbal balik (feedback). Dalam tahap ini tim mengevaluasi hasil implementasi games yang telah diterapkan oleh para relawan dengan memperhatikan beberapa poin penting sebelum dan sesudah penggunaan games. Relawan melaporkan pengaruh dan faktor apa saja yang dihasilkan setelah penggunaan games dalam meningkatkan motivasi belajar.

\section{SIMPULAN}

Dengan kegiatan pelatihan ini diharapkan para relawan Gemma Insani Indonesia (1) memiliki kemampuan dan wawasan mengenai dunia pendidikan khususnya pengajaran, (2) mampu mengaplikasikan materi dan pembahasan mengenai pendekatan games dalam memotivasi siswa mereka di kelas, (2) menggunakan metode-metode pengajaran yang bervariasi dalam kelas sehingga siswa tidak mudah bosan, (3) mampu berpikir kreatif dalam menciptakan atau membuat games yang sesuai dengan tingkat pendidikan siswa, (4) mampu menjadi model atau contoh bagi siswa sebagai pengajar yang berpengalaman dan kreatif. 


\section{UCAPAN TERIMA KASIH}

Ucapan terimakasih kami sampaikan kepada LPPM Unindra yang telah memberikan masukan dan kesempatan serta bantuan materil dalam pelaksanaan kegiatan pelatihan ini. Ucapan terima kasih kami sampaikan kepada pengelola jurnal yang telah mempublikasikan artikel kami. Terakhir, kami mengucapkan terima kasih kepada semua pihak yang telah membantu dalam kegiatan pelatihan dan penulisan artikel ini.

\section{DAFTRA PUSTAKA}

Abdullah, K.L (1993). Teaching Reading Vocabulary: from theory to practice, English Teaching Forum. Accessed on November $20^{\text {th }} 2012$.

Enggen, Paul dan Don Kauchak. (2007). Educational Psychology. New Jersey: Pearson Education, Inc,

Hadfield, Jill. (1984). Elementary Communication games. Hong Kong: Thomas Nelson Ltd.

Malik, Oemar. (2006). Proses Belajar Mengajar. Jakarta: Bumi Aksara.

Smith. Roger. Word Chains: A Word Game to Improve Spelling. Bewbush Academy: West Sussex.https://www.tes.com/teaching-resource/word-chains-a-word-game-to-improvespelling-6036715

Steely. John. (2013). Competition vs Cooperation. IB Dunia Teachers' Conference.

Sanjaya, Wina. (2006). Strategi Pembelajaran Berorientasi Standar Proses Pendidikan. Jakarta Kencana Prenada Media Group.

Santrock. John W. (2007). Psikologi Pendidikan: Edisi Kedua. Jakarta: Kencana Prenada Media Group.

Woolfolk, Anita E. dan Lorraine McCune-Nicholich. (2004). Mendidik Anak-Anak Bermasalah. Jakarta: Inisiasi Press. 